Supporting information

\title{
Real-Time Monitoring of Solid-Liquid Slurries: Optimized Synthesis of Tetrabenazine
}

Yusuke Sato, ${ }^{\dagger}$ Junliang Liu, ${ }^{\dagger}$ Andrew J. Kukor, ${ }^{\dagger}$ Jeffrey C. Culhane,${ }^{\ddagger}$ John L. Tucker, ${ }^{\ddagger}$ David J. Kucera, ${ }^{\ddagger}$ Brian M. Cochran, $\neq$ Jason E. Hein ${ }^{\star}{ }^{\dagger}$

† Department of Chemistry, The University of British Columbia, Vancouver, BC V6T 1Z1, Canada

‡Neurocrine Biosciences 12780 El Camino Real, San Diego, CA 92130, USA

*email for J. E. H.: jhein@chem.ubc.ca 


\section{Table of Contents}

1. On-line HPLC Monitoring Equipment

1.1. Dynamic Mixer (Akta M-925 mixing cartridge, $0.6 \mathrm{~mL}$ )

1.2. Mettler-Toledo EasySampler Probe Function and Geometry (sampling device)

1.3. EasyViewer

1.4. $\mathrm{pH}$ Probe

2. HPLC Methods

3. HPLC Spectra

4. The Role of Mixer Volume

5. TBZ Calibration Curve

6. Standard Addition as Internal Calibration Curve

7. NMR Spectra 
1. On-line HPLC Monitoring Equipment

1.1. Dynamic Mixer (Akta M-925 mixing cartridge, $0.6 \mathrm{~mL}$ )

(a)

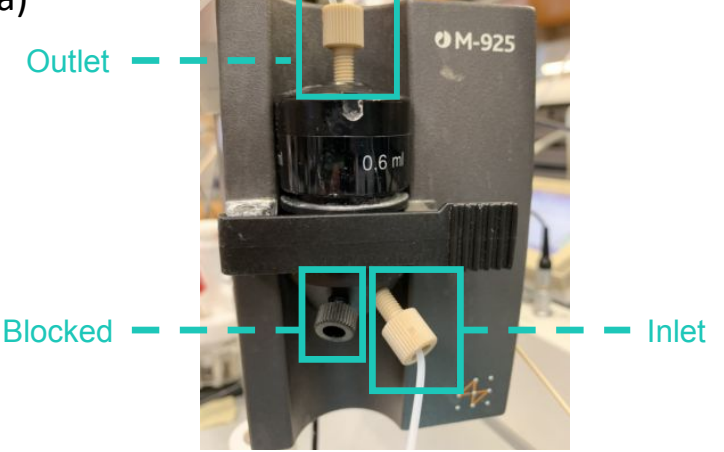

(b)

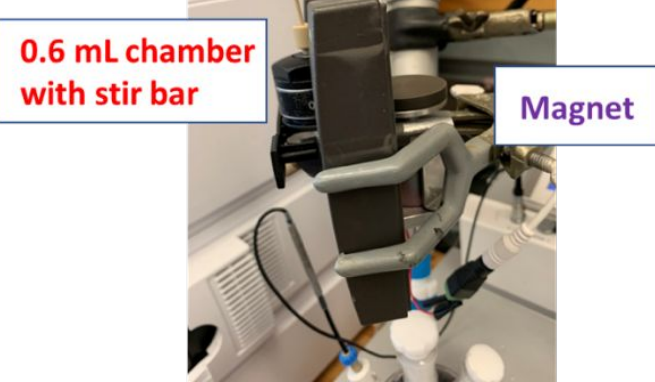

Figure S1. The dynamic mixer as shown from (a) the front and (b) the side.

Inline dynamic mixers are frequently used to facilitate the mixing of two homogeneous solution phases and/or solvents. The AKTA M-925 mixer has inlets for two separate solutions to enter, and a mixing chamber with w magnetic stir bar that, with the assistance of an external rotating magnetic field, stirs and facilitates optimal mixing of the two solutions. We have adapted this for assisting in the dissolution of minute solids in the sample aliquot before delivery to the HPLC for analysis. Heterogeneous sample (containing solids suspended in reaction solution) are pushed via a diluent solvent (chosen to be able to dissolve all components, which in this case was acetonitrile). However, dissolution takes time and is assisted by mechanical stirring to break up solids. As such, delivering the heterogeneous sample aliquot from the EasySampler to the inline dynamic mixer ensures total solids dissolution before sample is passed to the sample loop and introduced onto the HPLC, ensuring accurate and reproducible quantitation, and avoiding clogging. This sample enters the a $600 \mu \mathrm{L}$ mixer chamber through one of the two available inlet ports (with the other port is blocked, as no second solution is being used and only the diluent already present is assisting in dilution). After entering the mixer and undergoing mechanical agitation, the sample is then pushed into the sample loop and injected onto the HPLC.

\subsection{Mettler-Toledo EasySampler Probe Function and Geometry (sampling device)}

The EasySampler is a commercially available probe-based device. The sampling head consists of $20 \mu \mathrm{L}$ pocket to capture both solid and liquid phases from the reactor. At each sampling event, the probe head and pocket are first filled with inert gas to prevent from dilution by releasing solution (Figure S2a). Then, extend the head pocket into the reactor and the pocket is filled with slurry sample (Figure S2b). While in the extended position, the internal fluidic pathway of EasySampler is primed with quenching solvent (yellow line in Figure S2b). Next, the head pocket is retracted, and captured aliquot is delivered onto sample loop with diluent solvent. This process can be visualized in an animation published on YouTube. https://www.youtube.com/watch?v=IMVZw3wMhU0 

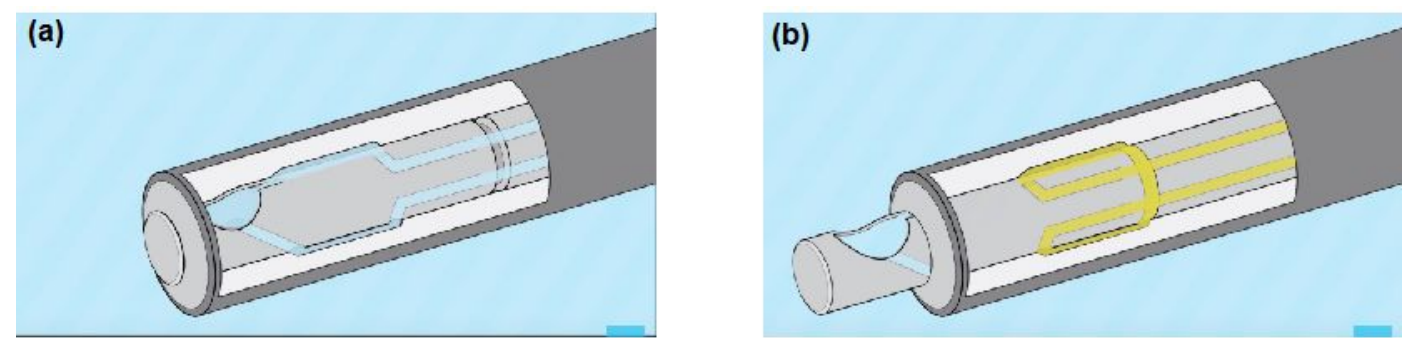

Figure S2. Mettler-Toledo EasySampler. (a) closed position. (b) extended position.

\subsection{EasyViewer}

Mettler-Toledo EasyViewer 100 was used as an in-situ, probe-based imaging and video microscope that captures high-resolution images of crystals, particles, and droplets as they exist in a process. With Mettler-Toledo's iC Vision software, EasyViewer provided real time physical properties of reaction mixtures such as dissolution, primary nucleation, and crystal growth.

\section{4. pH Probe}

The $\mathrm{pH}$ values were Mettler-Toledo InLab® Semi-Micro-L pH electrode. $\mathrm{pH}$ probe was calibrated with $\mathrm{pH} 7$ and $\mathrm{pH} 4$ buffer solutions prior to each reaction monitoring. Mettler Toledo iControl was used in conjunction with the $\mathrm{pH}$ probe for the acquisition and recording of real time $\mathrm{pH}$ trends.

\section{HPLC Methods}

The on-line Liquid Chromatography (LC) samples were analyzed by HPLC conducted on an Agilent 1260 HPLC equipped with DAD detector using the following configuration:

Method:

Agilent HPH C18 Column, $3.0 \times 50 \mathrm{~mm} ; 2.7 \mu \mathrm{m}$

Solvent $A=$ Water; Solvent $B=$ Methanol with $0.1 \%$ DIPA

Flow Rate $=0.450 \mathrm{~mL} / \mathrm{min}$

Column Temperature $=40^{\circ} \mathrm{C}$

Gradient:

$$
\begin{aligned}
& A: B=90: 10-\text { initial } \\
& A: B=0: 100-6.0 \text { min } \\
& 7.0 \text { min stoptime, } 2 \text { min pastime }
\end{aligned}
$$

DAD:

$190-480 \mathrm{~nm}$ was collected. The following wave lengths were used for reaction component peaks;

TBZ $1(280 \mathrm{~nm})$, isoquinoline $3(264 \mathrm{~nm})$, TBZ diastereomers $7(280 \mathrm{~nm})$, enone $5(240 \mathrm{~nm})$ 
The off-line Liquid Chromatography (LC) samples were analyzed by HPLC conducted on an Agilent 1290 HPLC equipped with DAD and quadrupole MS (G6140A) detectors using the following configuration:

Method: $\quad$ Poroshell 120 EC-C18 Column, 3.0 x $50 \mathrm{~mm} ; 1.9 \mu \mathrm{m}$

Solvent $A=$ Water with $0.1 \%$ formic acid; Solvent $B=$ Acetonitrile

Flow Rate $=0.950 \mathrm{~mL} / \mathrm{min}$

Column Temperature $=30^{\circ} \mathrm{C}$

Gradient: $\quad A: B=100: 0-$ initial

$A: B=70: 30-3.5 \mathrm{~min}$

$A: B=5: 95-4.5 \mathrm{~min}$

$A: B=0: 100-5.0 \mathrm{~min}$

5.5 min stoptime, 1 min postime

DAD: $\quad 190-480 \mathrm{~nm}$ was collected and $210 \mathrm{~nm}$ spectrum was utilized for integration.

ESI-MSD: $\quad$ positive mode scan for $\mathrm{m} / \mathrm{Z} 110-1500$ running at $0.8 \mathrm{sec} /$ cycle. drying gas $=7.0 \mathrm{l} / \mathrm{min}$, nebulizer pressure $=20 \mathrm{psi}$, gas temperature $=300^{\circ} \mathrm{C}$, capillary voltage $=4000 \mathrm{~V}$

\section{HPLC Spectra}

Neurocrine's optimized conditions (Reaction 1 conditions in the paper)

\section{Reaction time $=5$ hours $(240 \mathrm{~nm})$}

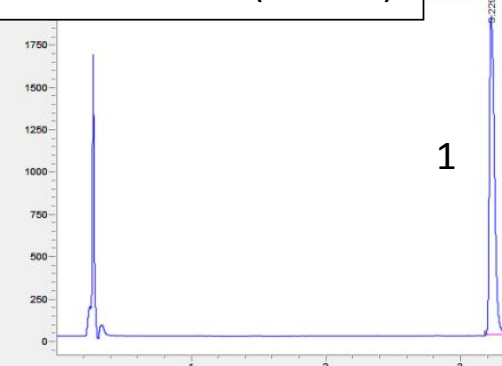

3

No. Rt (min)

\begin{tabular}{|c|c|c|}
\hline 1 & 3.23 & isoquinoline 3 \\
\hline 2 & 4.59 & enone 5 \\
\hline 3 & 5.53 & TBZ 1 \\
\hline 4 & 5.69 & TBZ diastereomers 7 \\
\hline
\end{tabular}

4

Reaction time $=5$ hours $(280 \mathrm{~nm})$

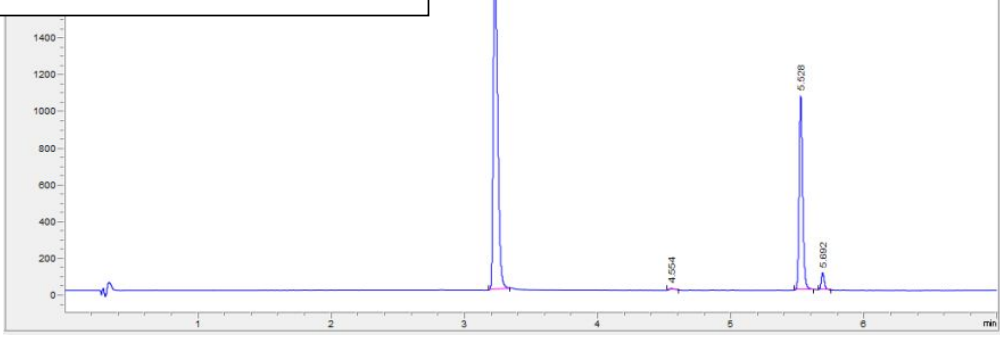

Figure S3. HPLC spectra $(240 \mathrm{~nm}$ and $280 \mathrm{~nm})$ at 5 hours under reaction 1 conditions. 


\section{The Role of Mixer Volume}

Using heterogeneous solution (including unknown conc. of TBZ and Isoquinoline: TBZ is heterogeneous and Isoquinoline is homogeneous component), we increased the amount of mixer volume (no dynamic mixer volume, $0.05 \mathrm{~mL}, 0.2 \mathrm{~mL}, 0.3 \mathrm{~mL}$ and $0.4 \mathrm{~mL}$ ) followed by a 30 seconds wait time.

(a) No mixer volume

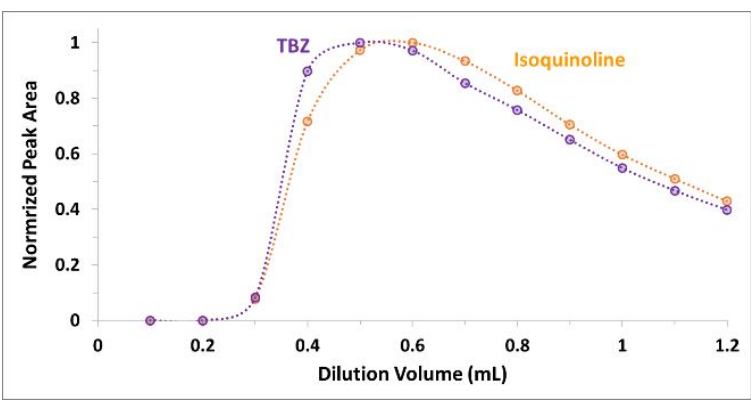

(b) $0.05 \mathrm{~mL}$

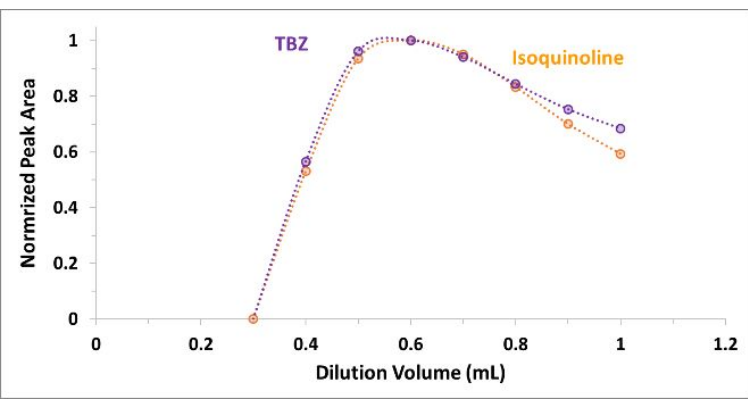

(d) $0.3 \mathrm{~mL}$

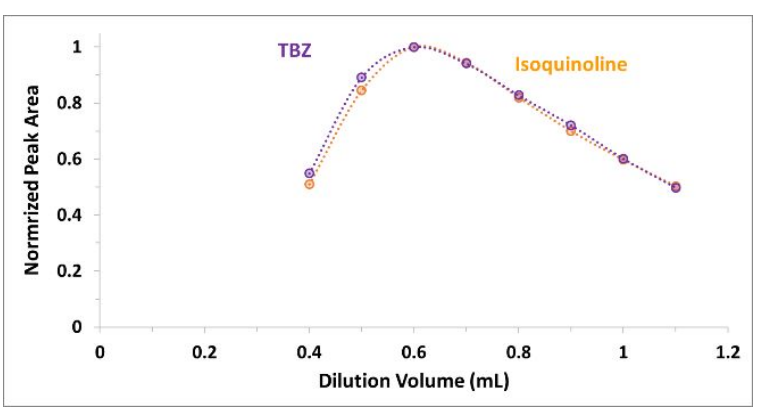

With no mixer volume, we observed different delivery kinetics of heterogeneous and homogeneous components. This indicated that the dynamic mixer could not dissolve the heterogeneous component immediately.
(c) $0.2 \mathrm{~mL}$

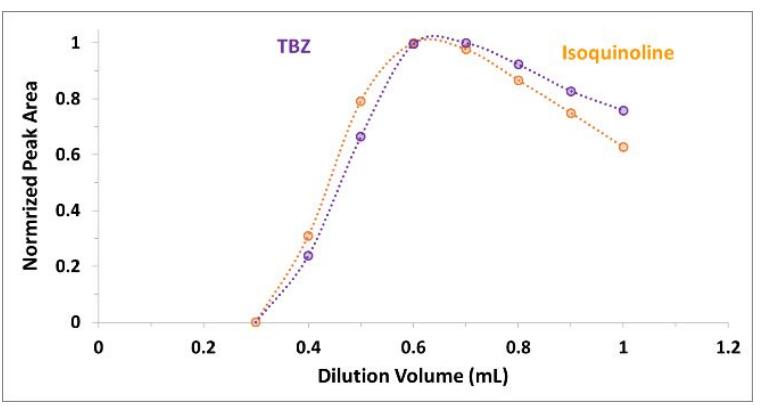

(e) $0.4 \mathrm{~mL}$

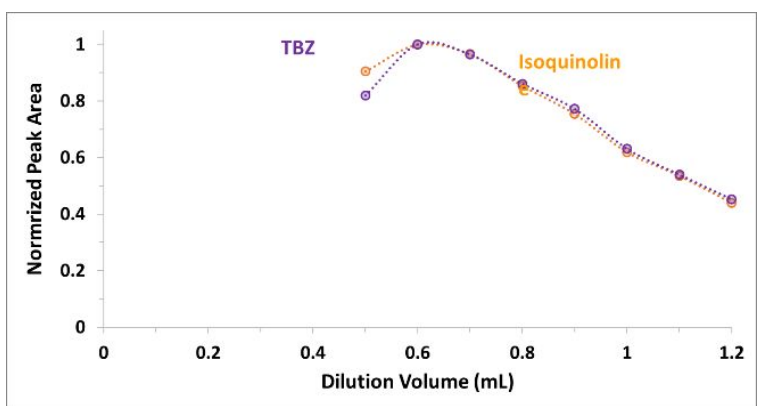

Figure S4. Delivery kinetics of heterogeneous TBZ and homogeneous isoquinoline when using (a) the no mixer volume (b) $0.05 \mathrm{~mL}$ mixer volume and wait 30 seconds. (c) $0.2 \mathrm{~mL}$ mixer volume and wait 30 seconds. (d) $0.3 \mathrm{~mL}$ mixer volume and wait 30 seconds. (e) $0.4 \mathrm{~mL}$ mixer volume and wait 30 seconds.

Since the minimum volume required to deliver the sample aliquot to the dynamic mixer is $0.225 \mathrm{~mL}$, we observed that less than $0.2 \mathrm{~mL}$ mixer volume was not enough to obtain the same delivery kinetic both of homogeneous and heterogeneous components. 


\section{TBZ Calibration Curve}

Calibration curves of TBZ was generated using a Mettler-Toledo $50 \mathrm{~mL}$ one-piece glass reactor at $45^{\circ} \mathrm{C}$ controlled in EasyMax 102 Advanced Thermostat System. TBZ precipitates at concentrations above $0.13 \mathrm{M}$ in a solution of $30 \%$ water in isopropyl alcohol at $45^{\circ} \mathrm{C}$. To get accurate total volume, the volume of solid was also considered using relationship of volume changes against solid dose of TBZ (Figure 4).

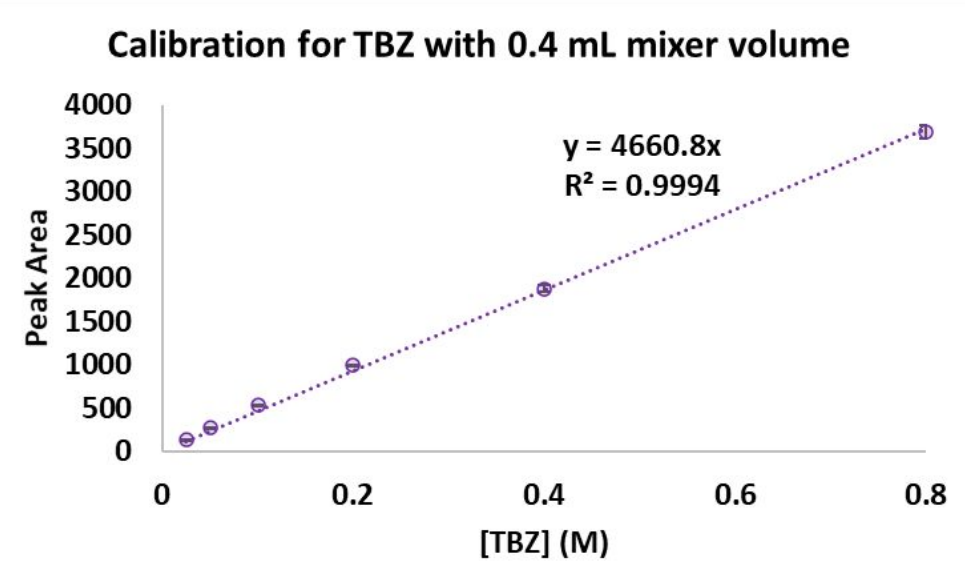

\begin{tabular}{|r|r|l|}
\hline [TBZ](M) & TBZ Peak Area & RSD (\%) \\
\hline 0.8 & 3695.520379 & 2.171767 \\
\hline 0.4 & 1876.970802 & 2.074271 \\
\hline 0.2 & 995.5492036 & 0.700371 \\
\hline 0.1 & 532.8479694 & 1.474731 \\
\hline 0.05 & 266.8709229 & 2.874565 \\
\hline 0.025 & 133.3375785 & 2.592775 \\
\hline
\end{tabular}

Figure S5. Calibration curve of TBZ using $0.4 \mathrm{~mL}$ mixer volume and wait 30 seconds method.

Our on-line HPLC platform generated a linear calibration curve of the slurry TBZ solution with low relative standard deviations $(<3 \%)$.

\section{Standard Addition as Internal Calibration Curve}

We used standard addition method, which is reported by Burés et.al. ${ }^{24}$, to generate "internal calibration curve" along with the setup of the reaction. Methods to make in-situ calibration curve (standard addition method) for all reaction components without interfering the reaction monitoring process is below:

Standard addition at the initial points of reactions (isoquinoline 3):

A sequential addition of known amount of starting material before adding other components, (so the starting material concentration should not be changing by reaction at this time) and we take several samples after each addition. By knowing the total volume and starting material amounts before and after each addition, we can derive the equation to calculate the slope between concentration and signal for the starting material. This is similar to making a 2-points calibration curve. 


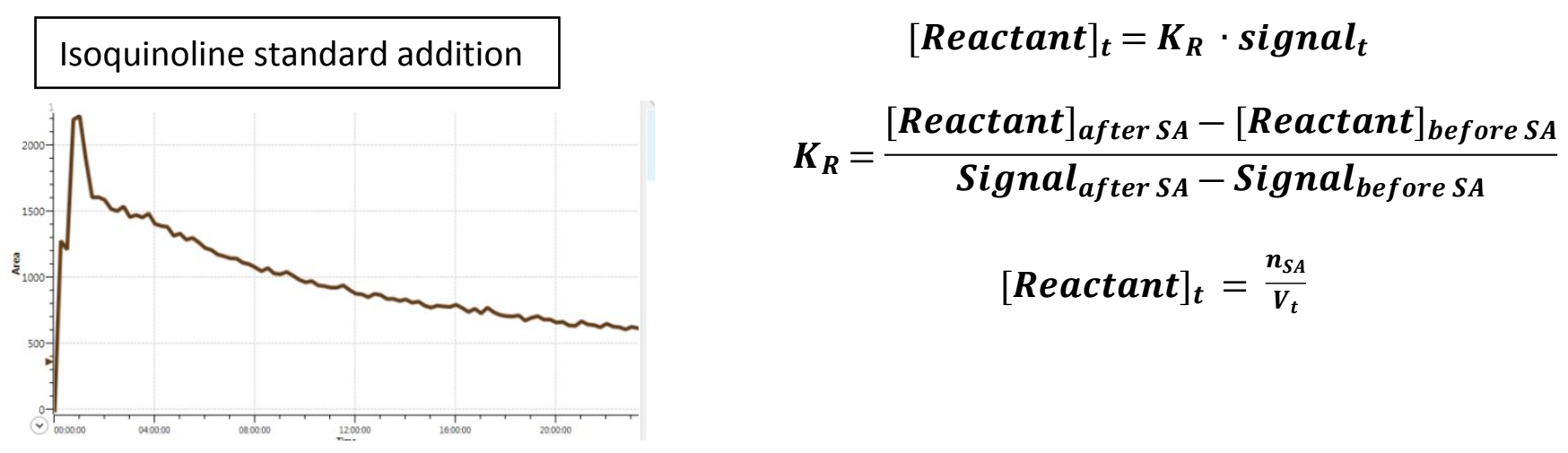

Figure S6. Reaction monitoring profile of isoquinoline with Initial points standard addition.

Standard addition at the ending points of reactions (TBZ 1 and enone 5):

After the reaction is finished or slowed down enough, we know that the concentration of the product of this reaction is not going to change anymore, then we can start adding known amount for ending points standard addition and take samples. Notice that unlike the initial points standard addition, we do not know the concentration of components at this point, all we know is how much we added as amount, and the volume before and after the standard addition. As a result, $\mathrm{K}$ for product is calculated by using the addition amount and volume.

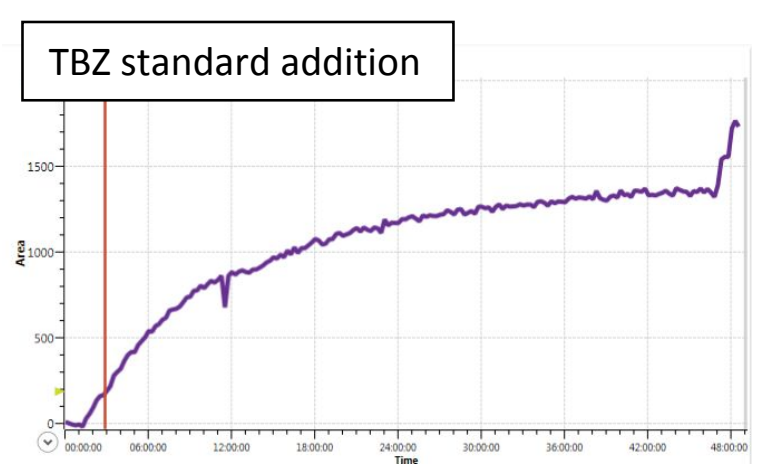

$$
\begin{gathered}
n_{t}=K_{p} \cdot \text { signal }_{t} \cdot V_{t} \\
\frac{n_{t}}{V_{t}}=K_{p} \cdot \text { signal }_{t} \\
\Delta n=K_{p} \cdot\left(\text { signal }_{S A} \cdot V_{S A}-\text { signal }_{\text {before SA }} \cdot V_{\text {before } S A}\right) \\
K_{p}=\frac{\Delta n}{\left(\text { signal }_{S A} \cdot V_{S A}-\text { signal }_{\text {before SA }} \cdot V_{\text {before } S A}\right)}
\end{gathered}
$$

Figure S7. Reaction monitoring profile of TBZ with ending points standard addition 


\section{NMR Spectra}

Tetrabenazine (TBZ) (1)- ${ }^{1} \mathrm{H} \mathrm{NMR}\left(400 \mathrm{MHz}, \mathrm{CDCl}_{3}\right)$

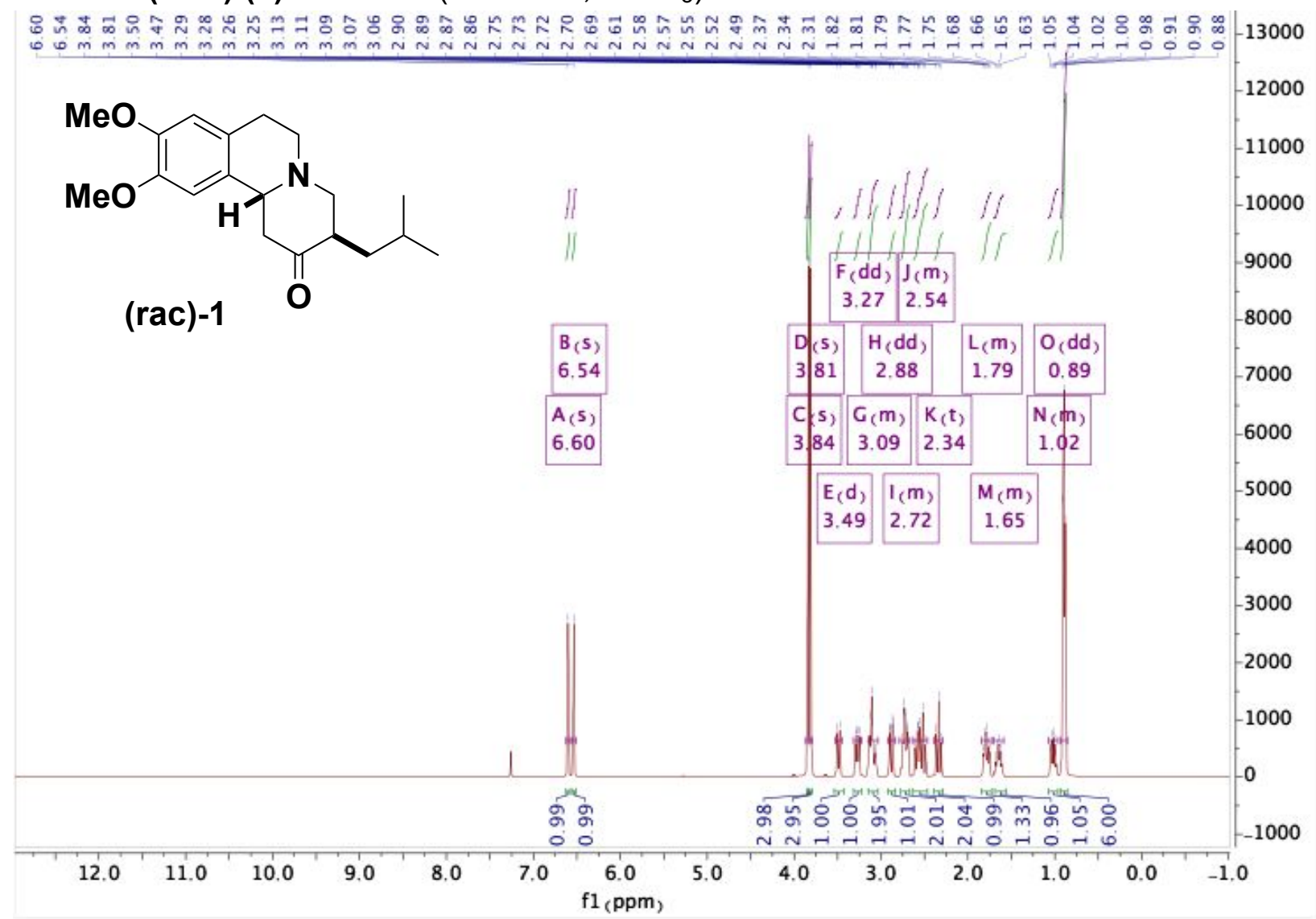

Tetrabenazine (TBZ) (1)- ${ }^{13} \mathrm{C}\left\{{ }^{1} \mathrm{H}\right\} \mathrm{NMR}\left(101 \mathrm{MHz}, \mathrm{CDCl}_{3}\right)$
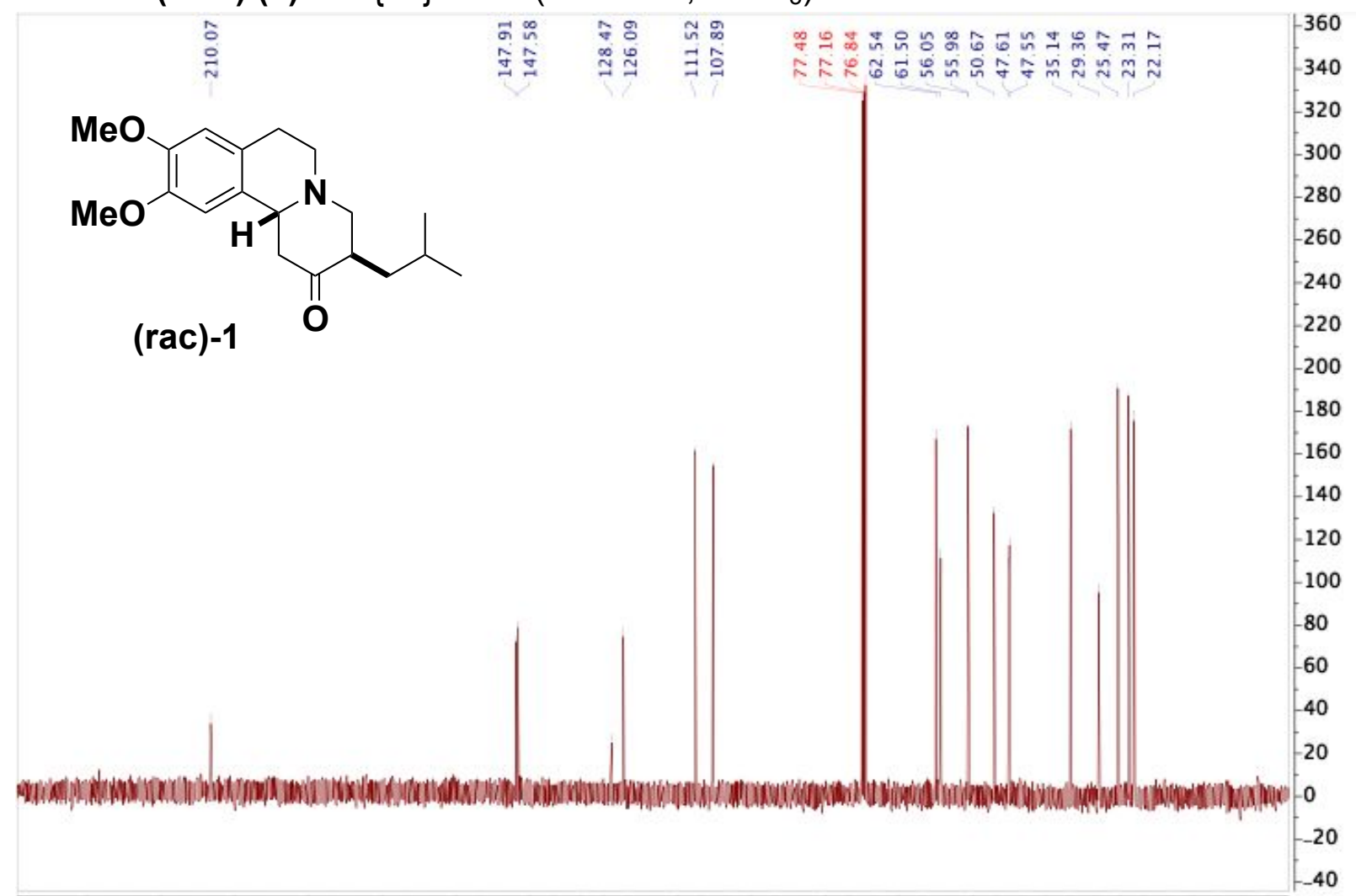

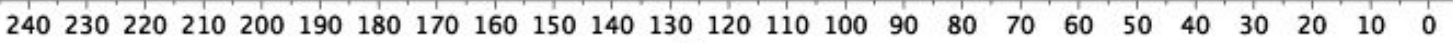

$\mathrm{f1}$ (ppm) 
3-[(dimethylamino)methyl]-5-methylhexan-2-one (4)- ${ }^{1} \mathrm{H} \mathrm{NMR}\left(400 \mathrm{MHz}, \mathrm{CDCl}_{3}\right)$

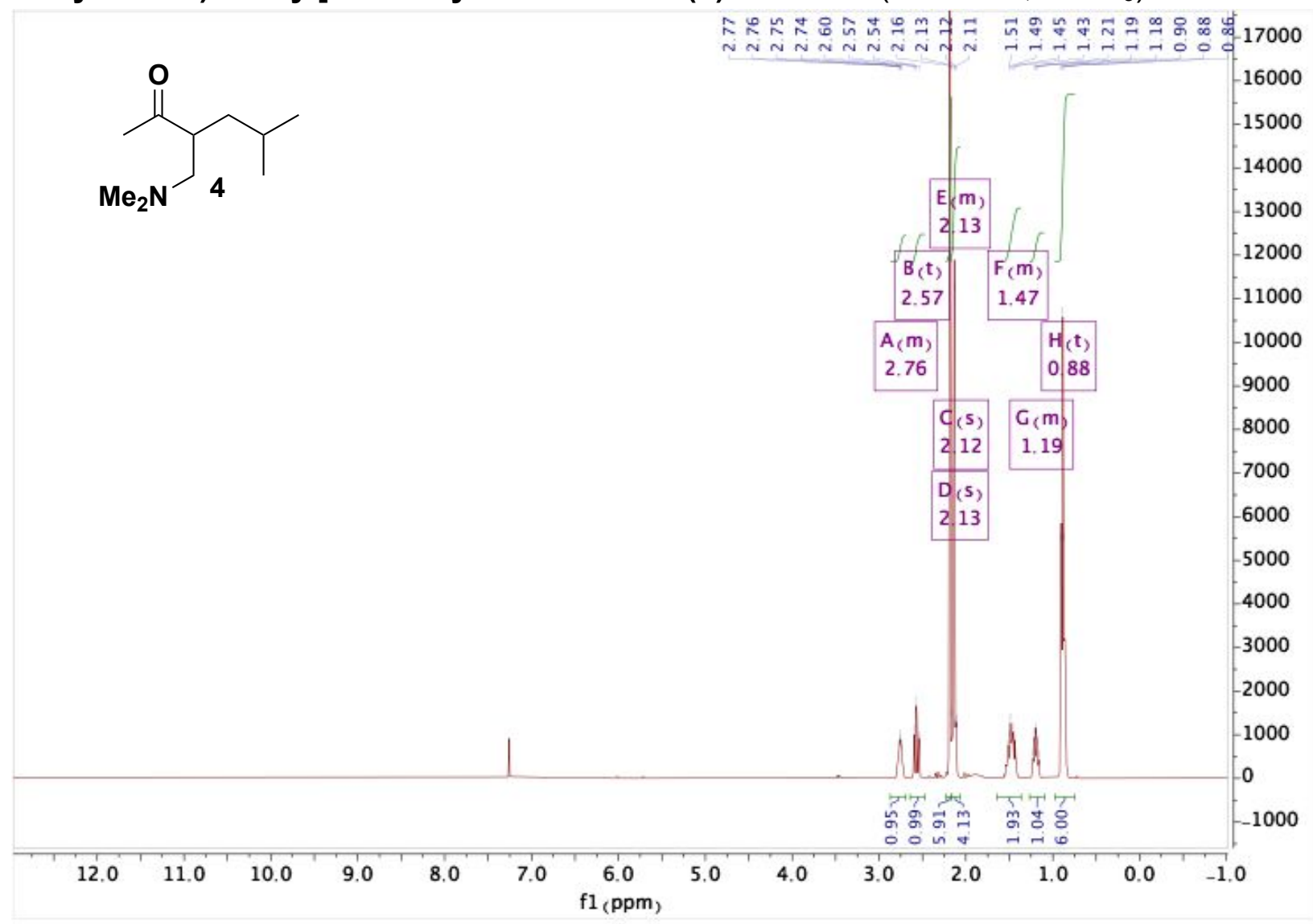

3-[(dimethylamino)methyl]-5-methylhexan-2-one (4)- ${ }^{13} \mathrm{C}\left\{{ }^{1} \mathrm{H}\right\} \mathrm{NMR}\left(101 \mathrm{MHz}, \mathrm{CDCl}_{3}\right)$

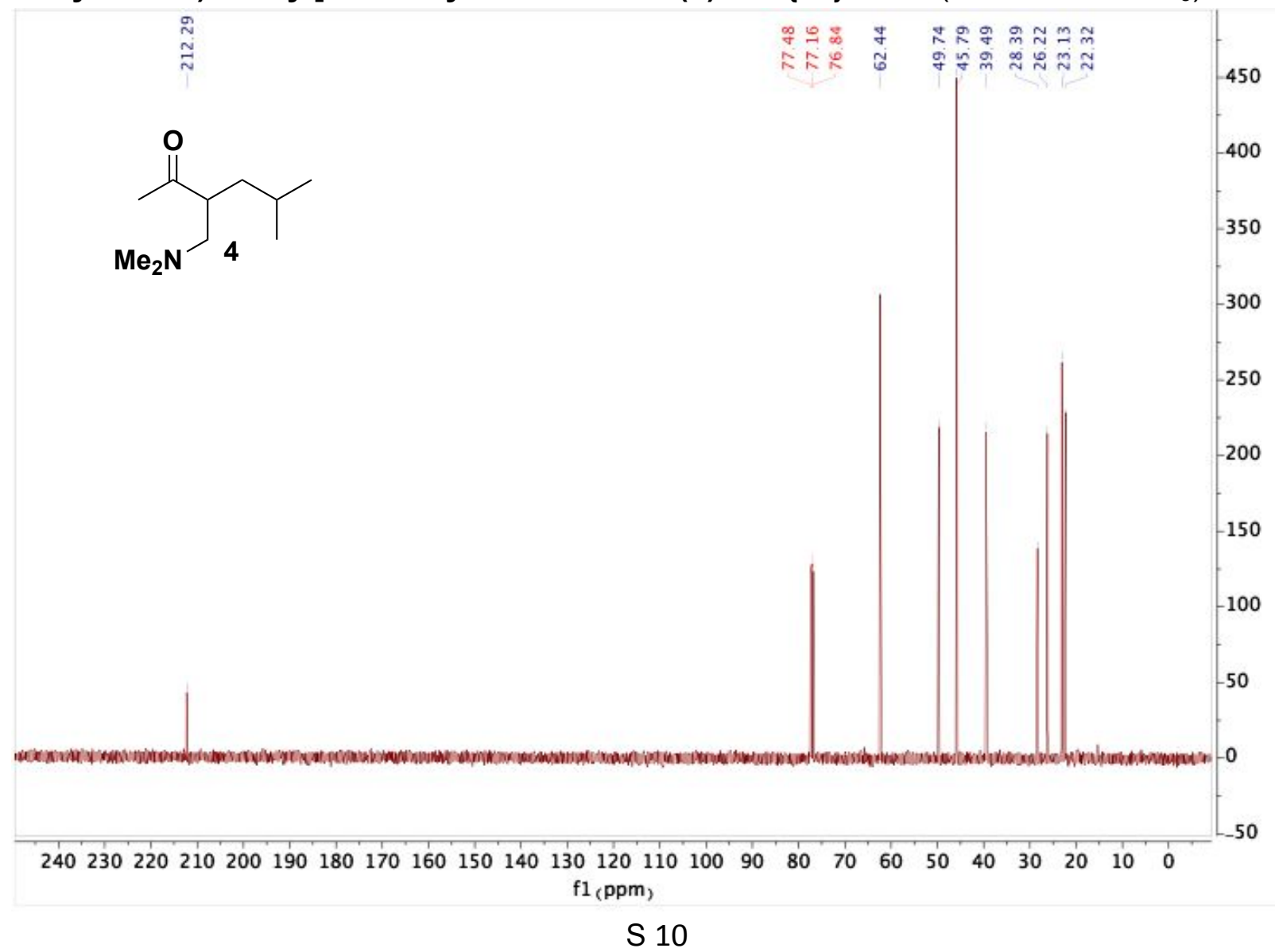


5-methyl-3-methylidenehexan-2-one (5)- ${ }^{1} \mathrm{H} \mathrm{NMR}\left(400 \mathrm{MHz}, \mathrm{CDCl}_{3}\right)$

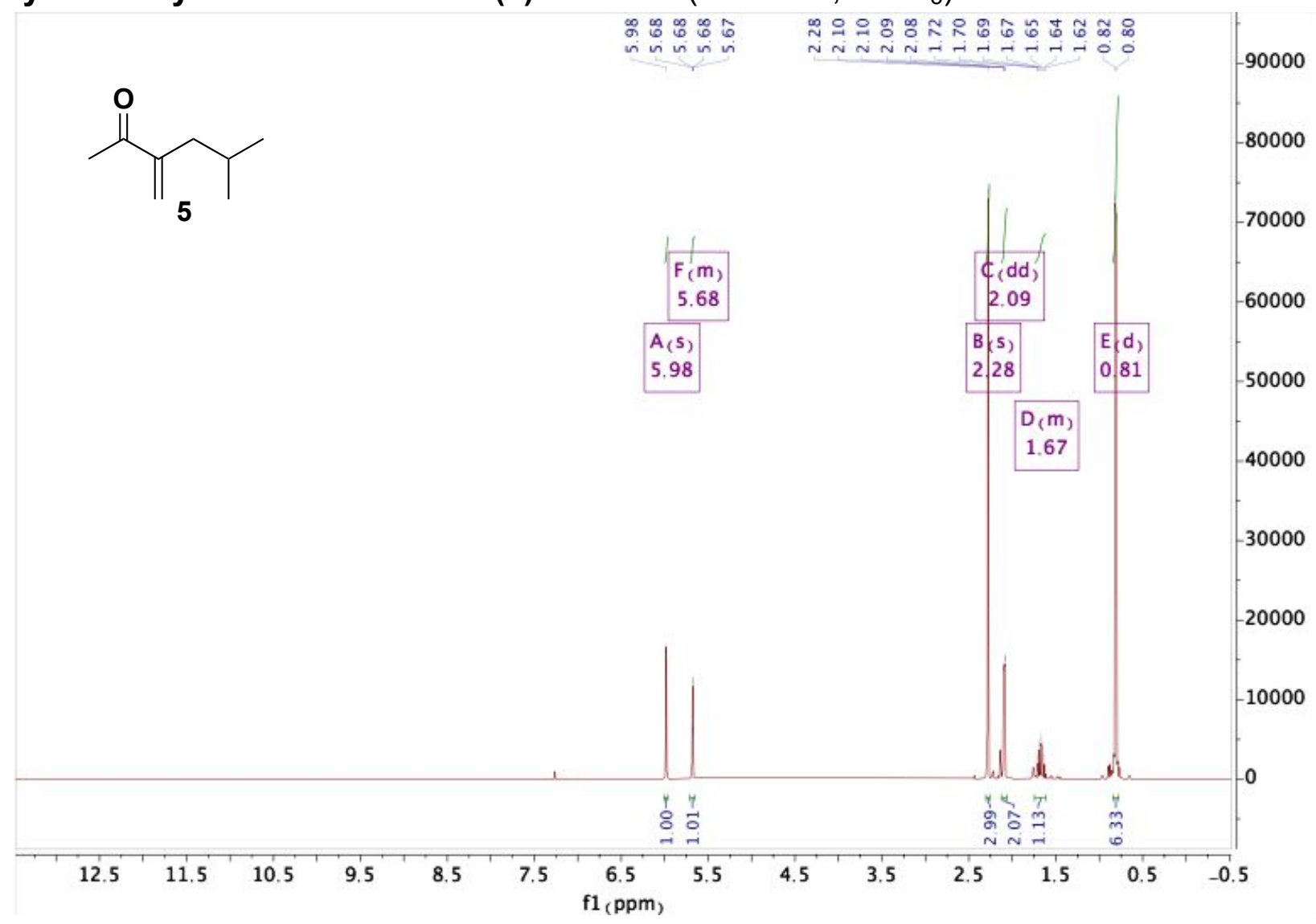

5-methyl-3-methylidenehexan-2-one (5)- ${ }^{13} \mathrm{C}\left\{{ }^{1} \mathrm{H}\right\} \mathrm{NMR}\left(101 \mathrm{MHz}, \mathrm{CDCl}_{3}\right)$

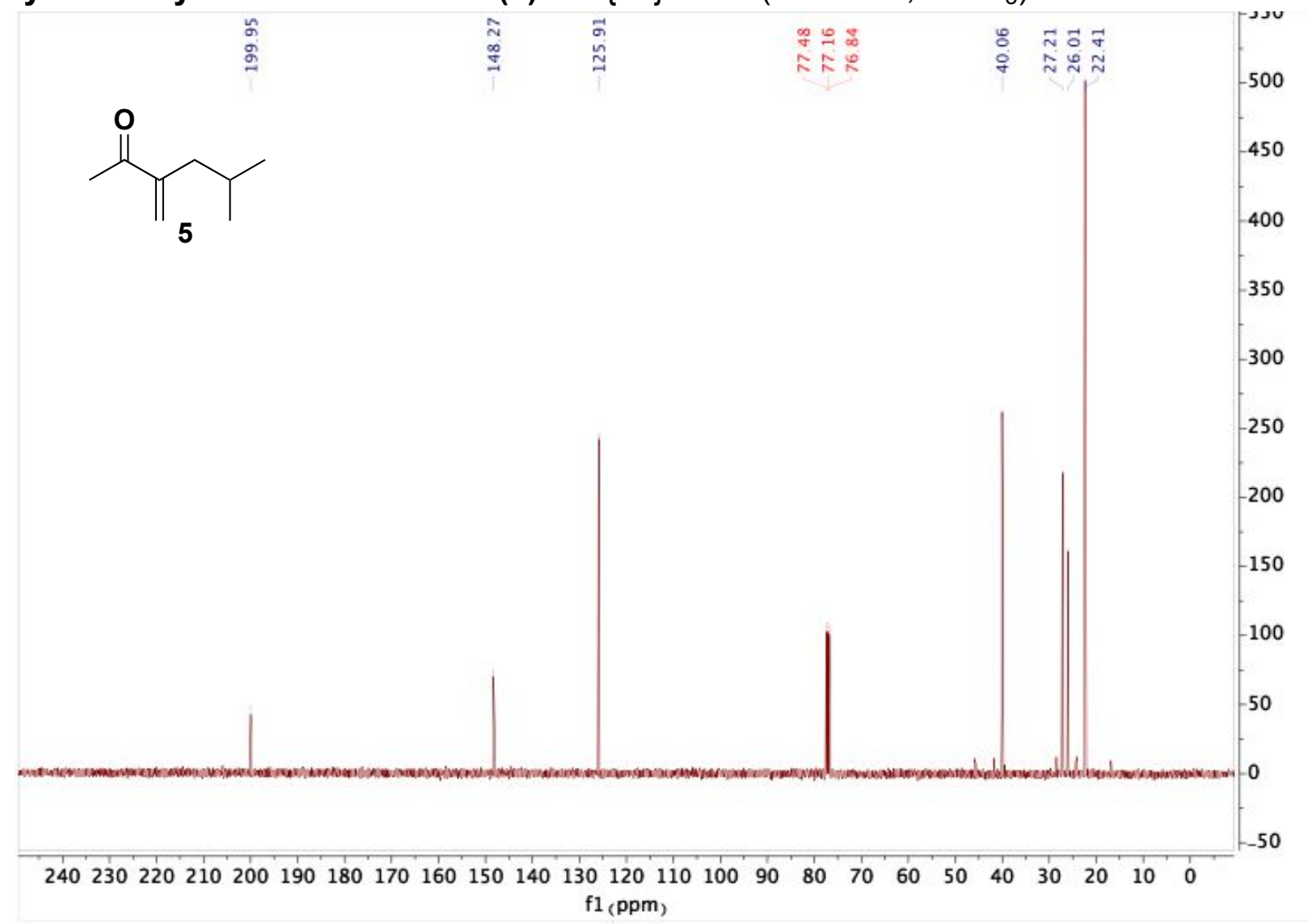




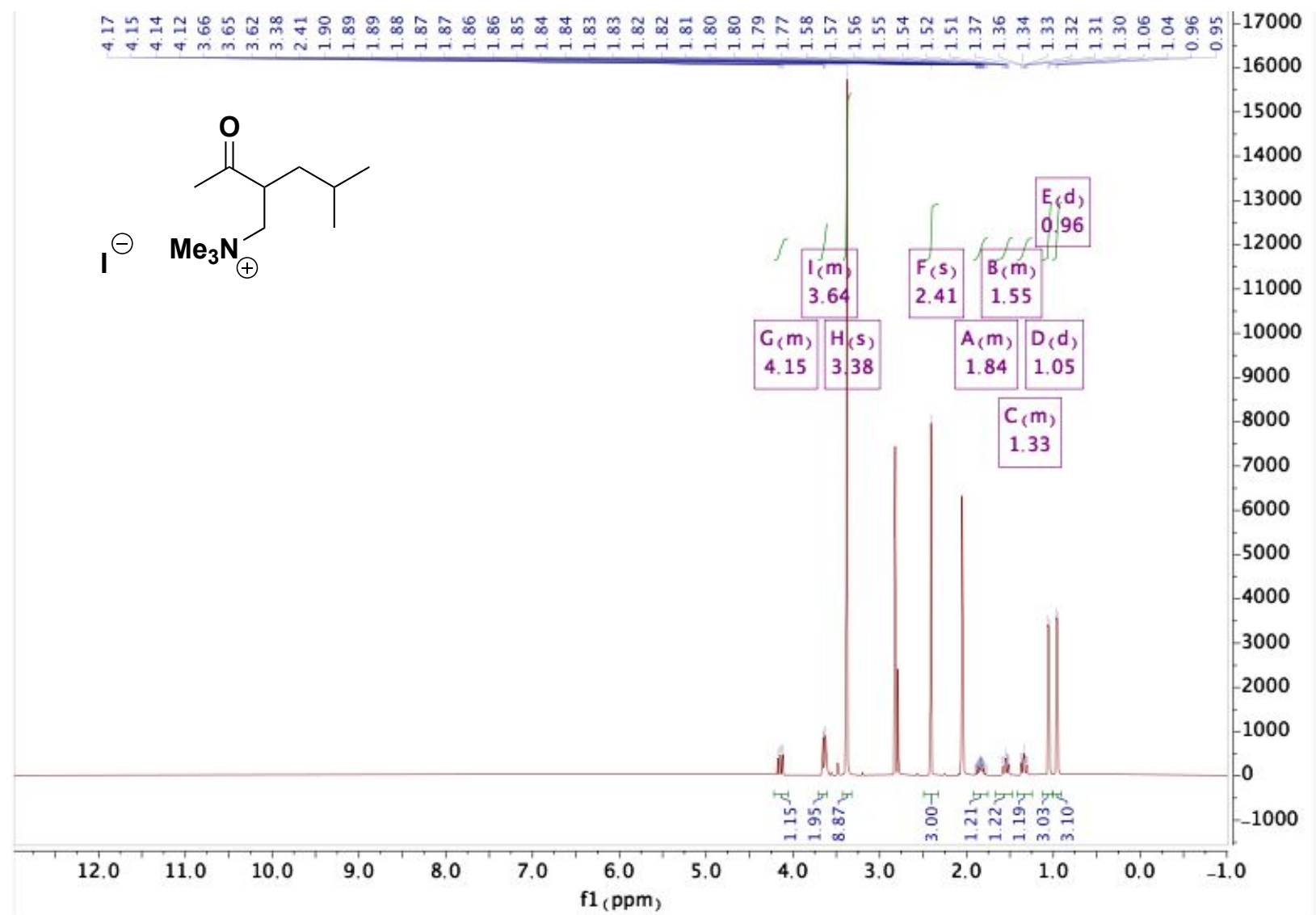


TBZ diastereomers (7)- ${ }^{1} \mathrm{H}$ NMR $\left(400 \mathrm{MHz}, \mathrm{CDCl}_{3}\right)$

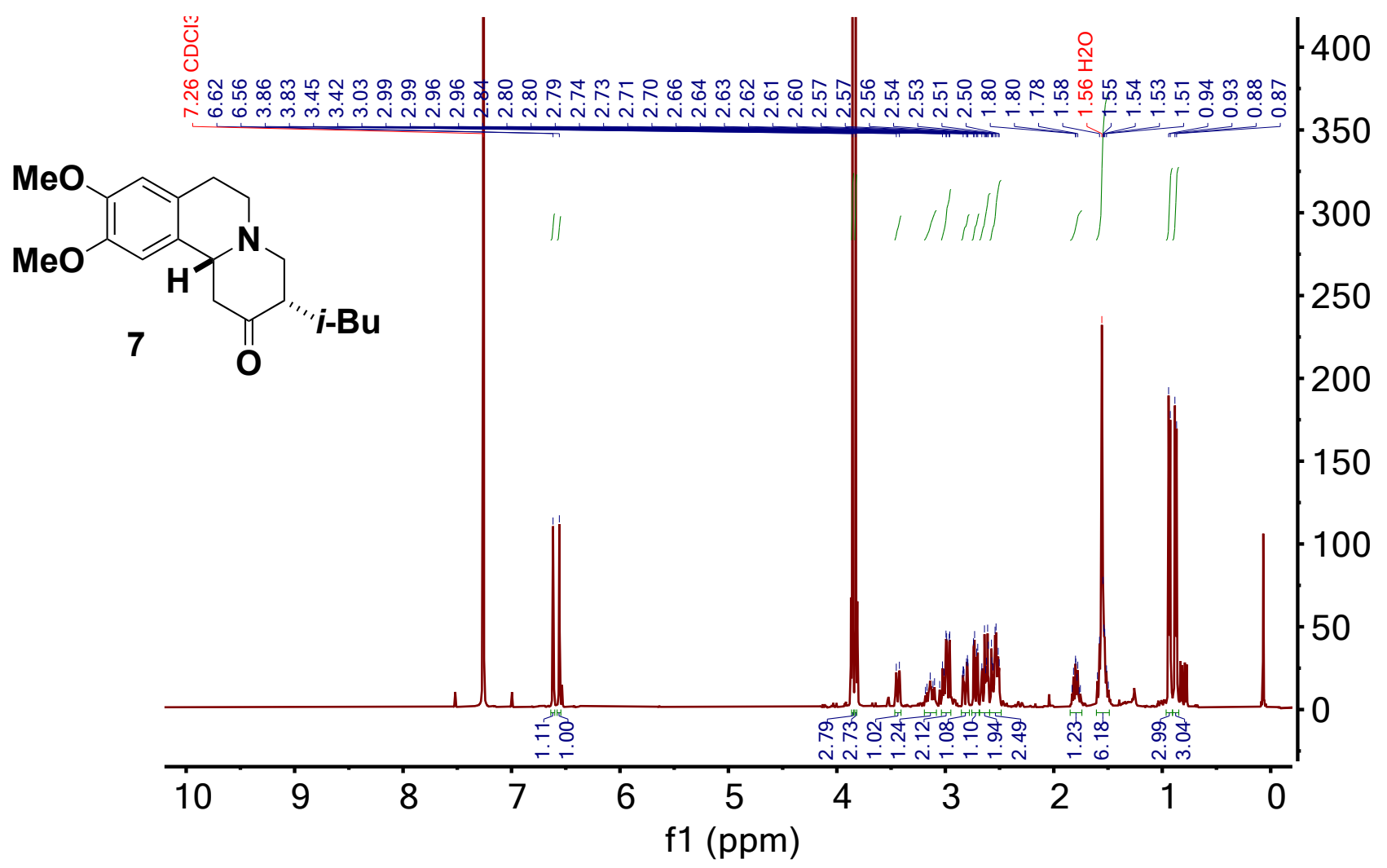

TBZ diastereomers (7)- ${ }^{13} \mathrm{C}\left\{{ }^{1} \mathrm{H}\right\}$ NMR $\left(101 \mathrm{MHz}, \mathrm{CDCl}_{3}\right)$<smiles>COc1cc2c(cc1OC)[C@H]1CC(=O)[C@@H](CC(C)C)CN1CC2</smiles>

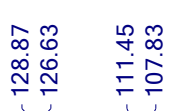

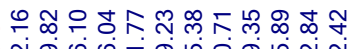

ชู่

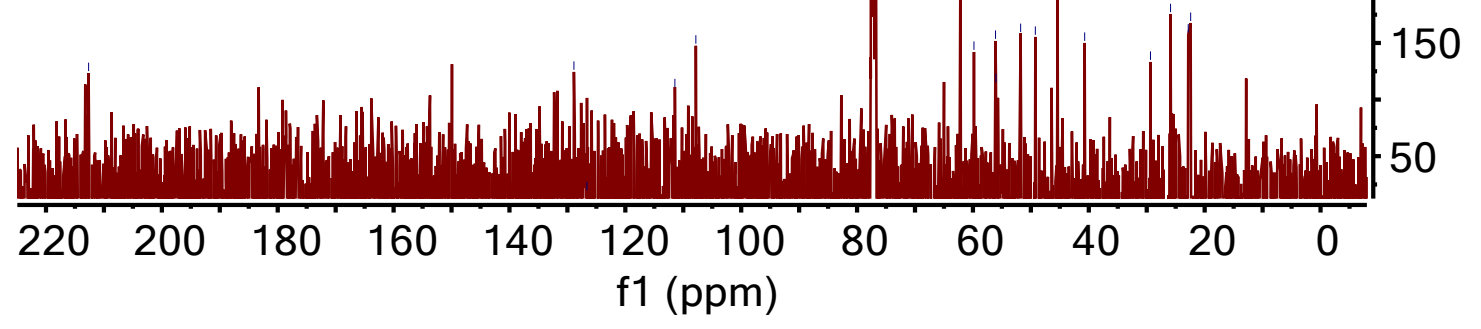


6,7-dimethoxy-2-[2-(2-methylpropyl)-3-oxobutyl]-3,4-dihydroisoquinolin-2-ium (8)- ${ }^{1} \mathrm{H}$ NMR (400 $\mathrm{MHz}, \mathrm{CDCl}_{3}$ )

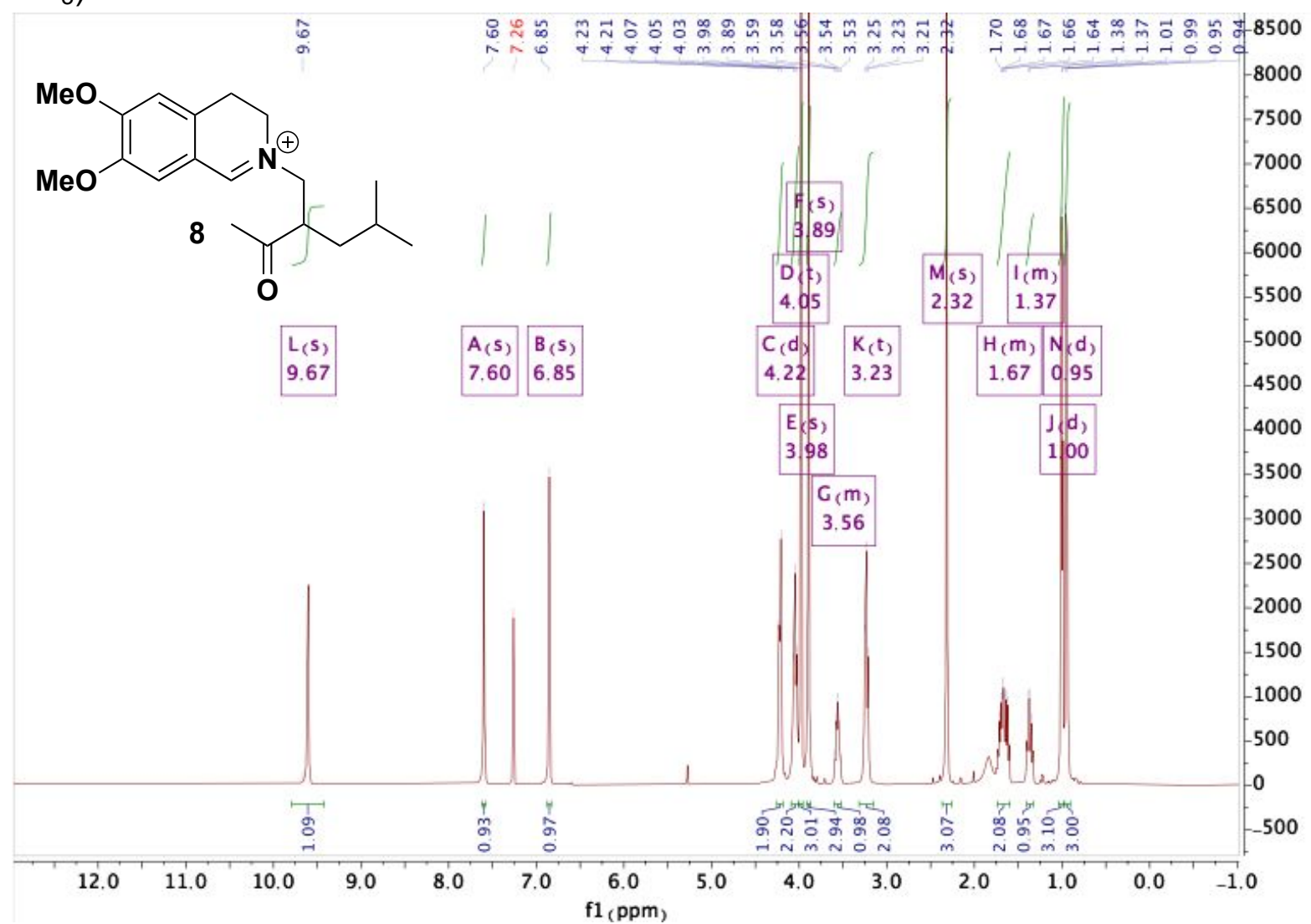

6,7-dimethoxy-2-[2-(2-methylpropyl)-3-oxobutyl]-3,4-dihydroisoquinolin-2-ium (8)- ${ }^{13} \mathrm{C}\left\{{ }^{1} \mathrm{H}\right\} \mathrm{NMR}$ $\left(101 \mathrm{MHz}, \mathrm{CDCl}_{3}\right)$

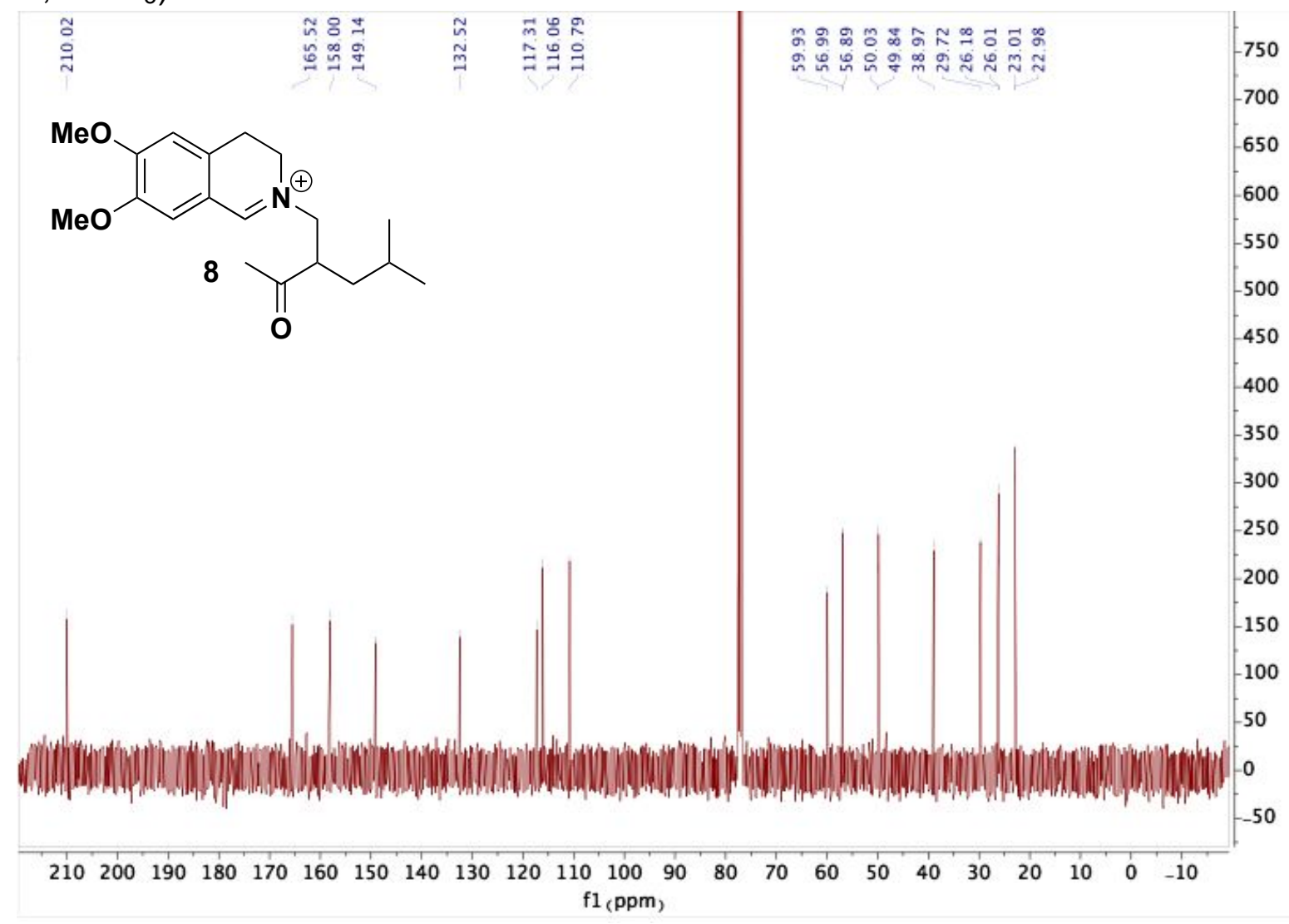


6,7-dimethoxy-2-[2-(2-methylpropyl)-3-oxobutyl]-3,4-dihydroisoquinolin-2-ium (8)- ${ }^{-1} \mathrm{H}-{ }^{-1} \mathrm{H}$ COSY $\left(400 \mathrm{MHz}, \mathrm{CDCl}_{3}\right)$

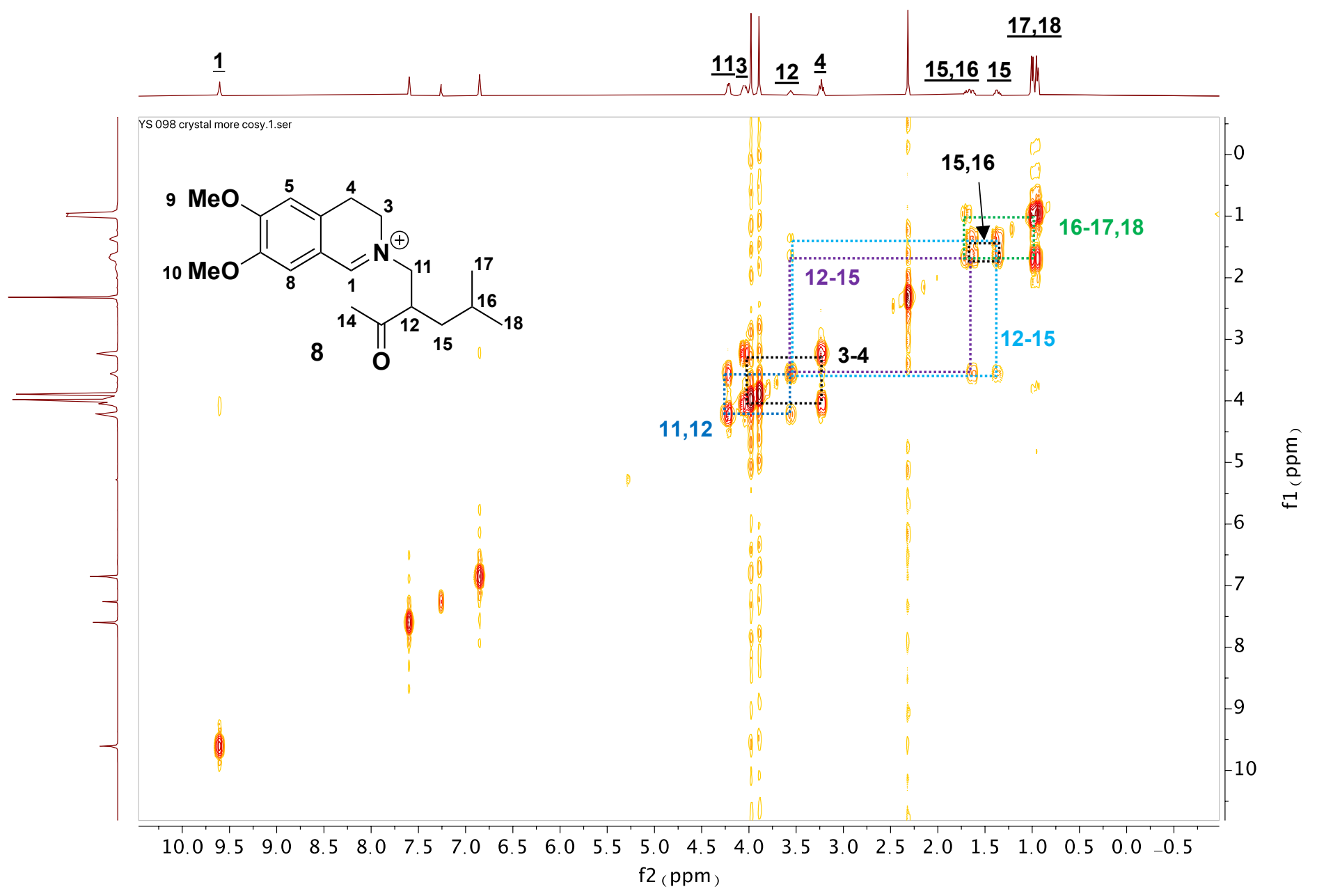

According to COSY NMR, $\mathrm{H}_{11}-\mathrm{H}_{12}$ and $\mathrm{H}_{3}-\mathrm{H}_{4}$ were observed. Diastereotpic protons at $\mathrm{C}_{15}$ were confirmed to be at 1.37 and $1.67 \mathrm{ppm}$ separately. 
6,7-dimethoxy-2-[2-(2-methylpropyl)-3-oxobutyl]-3,4-dihydroisoquinolin-2-ium (8)- ${ }^{-1} \mathrm{H}-{ }^{13} \mathrm{C}$ HMQC $\left(400 / 101 \mathrm{MHz}, \mathrm{CDCl}_{3}\right)$

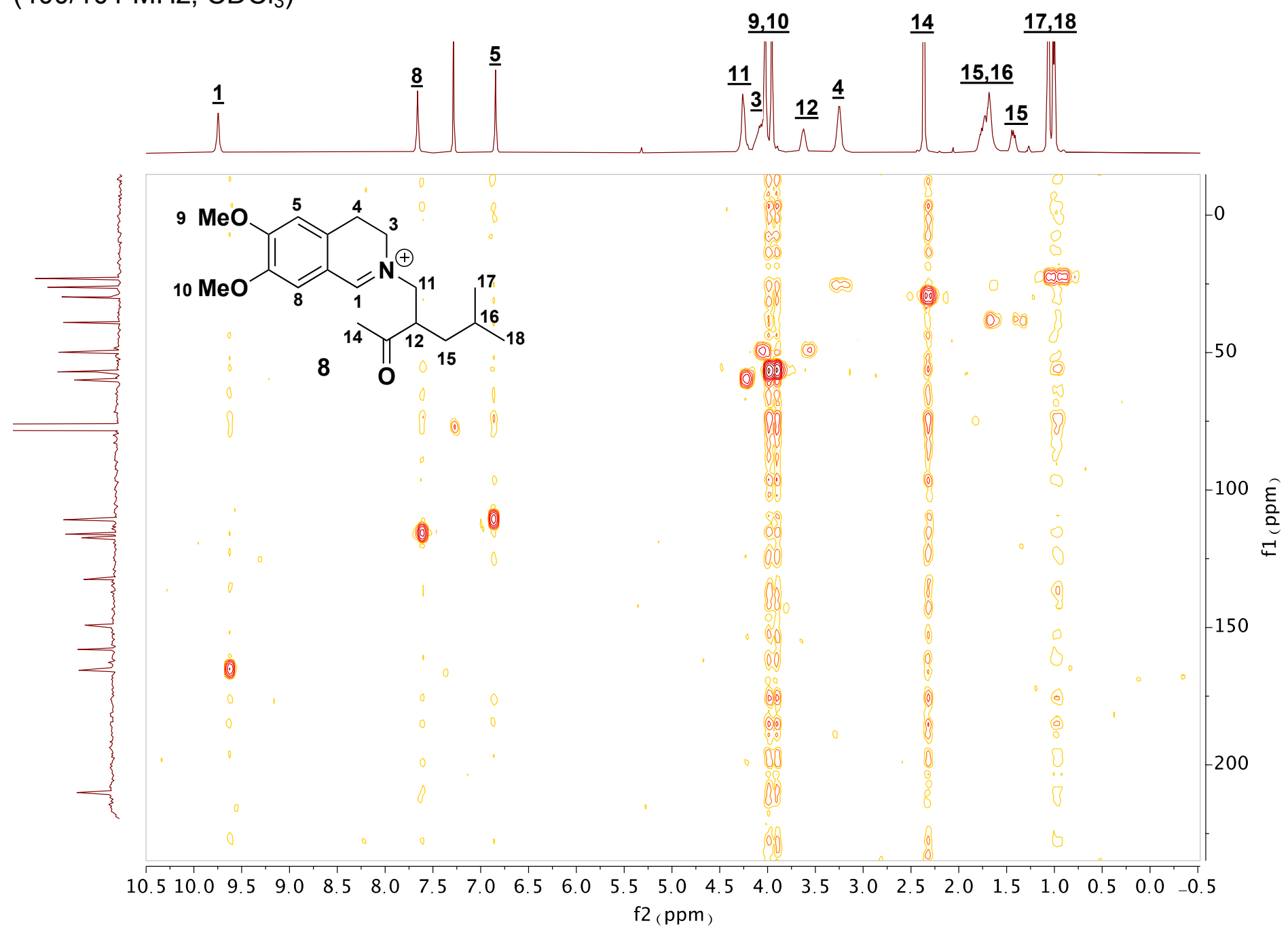

According to HMQC NMR, carbons possessing protons peaks in ${ }^{13} \mathrm{C}$ NMR were identified: $\mathrm{C}_{17,18}$ (23.0, 23.1), $\mathrm{C}_{15}$ (39.0), $\mathrm{C}_{16}$ (either 26.1 or 26.2), $\mathrm{C}_{14}$ (29.8), $\mathrm{C}_{4}$ (either 26.1 or 26.2), $\mathrm{C}_{12}$ (either 49.9 or $50.8), C_{9,10}(56.9,57.0), C_{3}$ (either 49.9 or 50.8), $C_{11}(60.0), C_{5}(110.8), C_{8}(116.1)$, and $C_{1}(165.6)$. 
6,7-dimethoxy-2-[2-(2-methylpropyl)-3-oxobutyl]-3,4-dihydroisoquinolin-2-ium (8)- ${ }^{1} \mathrm{H}-{ }^{13} \mathrm{C}$ HMBC $\left(400 / 101 \mathrm{MHz}, \mathrm{CDCl}_{3}\right)$

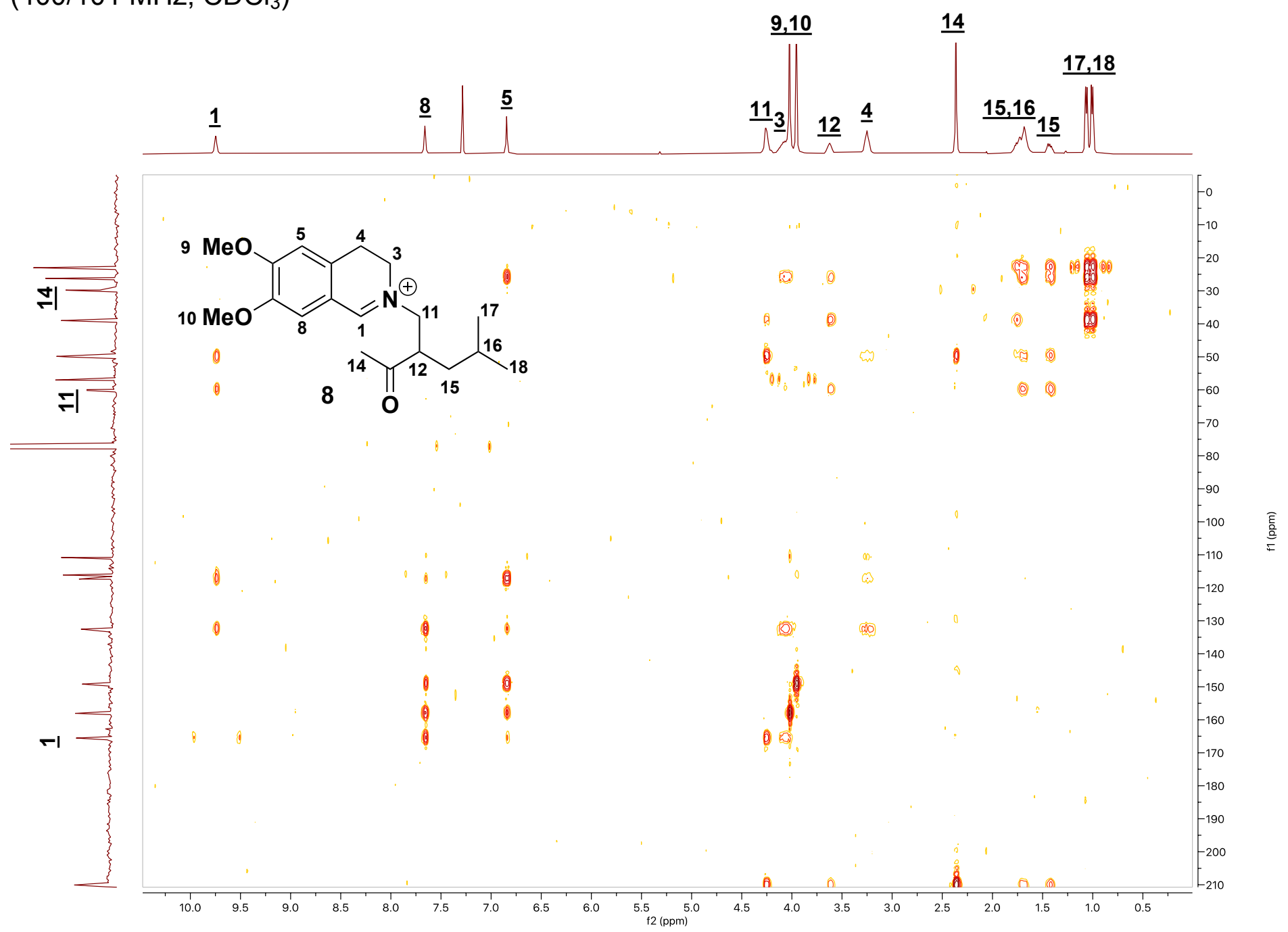

According to $\mathrm{HMBC}$ NMR, $\mathrm{C}_{1}$ has no correlation with $\mathrm{H}_{14}$ but $\mathrm{H}_{11}$ shown above, which corresponds to the iminium intermediate 6 . 